University of Nebraska - Lincoln

DigitalCommons@University of Nebraska - Lincoln

\title{
Expression and self-assembly of virus-like particles from two genotypes of marine vesiviruses and development of an ELISA for the detection of antibodies
}

\author{
Shasta D. McClenahan \\ University of Florida \\ Karin Bok \\ National Institutes of Health \\ Stanislav V. Sosnovtsev \\ National Institutes of Health \\ John D. Neill \\ National Animal Disease Center \\ Kathy A. Burek \\ Alaska Veterinary Pathology Services \\ See next page for additional authors \\ Follow this and additional works at: https://digitalcommons.unl.edu/usdaarsfacpub \\ Part of the Agricultural Science Commons
}

McClenahan, Shasta D.; Bok, Karin; Sosnovtsev, Stanislav V.; Neill, John D.; Burek, Kathy A.; Beckmen, Kimberlee B.; Smith, Alvin W.; Green, Kim Y.; and Romero, Carlos H., "Expression and self-assembly of virus-like particles from two genotypes of marine vesiviruses and development of an ELISA for the detection of antibodies" (2010). Publications from USDA-ARS / UNL Faculty. 864.

https://digitalcommons.unl.edu/usdaarsfacpub/864

This Article is brought to you for free and open access by the U.S. Department of Agriculture: Agricultural Research Service, Lincoln, Nebraska at DigitalCommons@University of Nebraska - Lincoln. It has been accepted for inclusion in Publications from USDA-ARS / UNL Faculty by an authorized administrator of DigitalCommons@University of Nebraska - Lincoln. 


\section{Authors}

Shasta D. McClenahan, Karin Bok, Stanislav V. Sosnovtsev, John D. Neill, Kathy A. Burek, Kimberlee B. Beckmen, Alvin W. Smith, Kim Y. Green, and Carlos H. Romero 


\title{
Expression and self-assembly of virus-like particles from two genotypes of marine vesiviruses and development of an ELISA for the detection of antibodies
}

\author{
Shasta D. McClenahan a , Karin Bok ${ }^{b}$, Stanislav V. Sosnovtsev ${ }^{\text {, }}$, John D. Neill ${ }^{\text {, }}$, Kathy A. Burek ${ }^{\text {, }}$, \\ Kimberlee B. Beckmen ${ }^{\text {, }}$, Alvin W. Smith ${ }^{\mathrm{f}}$, Kim Y. Green ${ }^{\mathrm{b}}$, Carlos H. Romero ${ }^{\mathrm{a}, *}$ \\ ${ }^{a}$ Department of Infectious Diseases and Pathology, College of Veterinary Medicine, University of Florida, 2015 SW 16 th Ave., Gainesville, FL 32610, USA \\ ${ }^{\mathrm{b}}$ Laboratory of Infectious Diseases, National Institute of Allergy and Infectious Diseases, National Institutes of Health, Bethesda, MD, USA \\ ${ }^{\mathrm{c}}$ National Animal Disease Center, USDA, Ames, IA 50010, USA \\ d Alaska Veterinary Pathology Services, 23834 The Clearing Dr, Eagle River, AK 99577, USA \\ e Alaska Department of Fish and Game, Division of Wildlife Conservation, 1300 College Road, Fairbanks, AK 99701, USA \\ ${ }_{\mathrm{f}}^{\mathrm{f}}$ Laboratory for Calicivirus Studies, 26833 Sulphur Springs Road, Oregon State University, Corvallis, OR 97330, USA
}

\section{A R T I C L E I N F O}

Article history:

Received 23 February 2009

Received in revised form 14 September 2009

Accepted 17 September 2009

\section{Keywords:}

Caliciviridae

Vesivirus

Virus-like particles

ELISA

Antibodies

Marine mammals

\begin{abstract}
A B S T R A C T
Sequences encoding the major and minor capsid proteins (VP1 and VP2) from two marine vesivirus isolates (Steller sea lion viruses V810 and V1415) were engineered for expression of virus-like particles (VLPs) in the baculovirus system. The resulting VLPs were morphologically similar to native vesivirus virions. Purified VLPs were probed in immunoblots with pooled antisera specific for nine San Miguel sea lion virus (SMSV) types, and a predominant protein of approximately $60 \mathrm{kDa}$ was detected. An enzyme linked immunosorbent assay (ELISA) for the detection of antibodies was developed in which the VLPs served as antigen. The VLPs were adsorbed to the wells of a microplate, and the specificity of the ELISA was established with hyperimmune sera raised against 24 serotypes of the genus Vesivirus. The ELISA was used to screen for the presence of vesivirus specific antibodies in the sera of free-ranging Steller sea lions. The ELISA results demonstrated that Steller sea lions that inhabit the Pacific Ocean waters of southeast Alaska are widely exposed to antigenically related marine vesiviruses, while no previous exposure could be demonstrated using VLP antigens in 17 Steller sea lions from the Aleutian Islands. The broad reactivity of these VLPs and their non-infectious nature will facilitate global sero-epidemiological studies aimed at determining the incidence and prevalence of marine vesiviruses in mammals that inhabit the Pacific and Atlantic oceans as well as susceptible terrestrial animals.
\end{abstract}

(c) 2009 Elsevier B.V. All rights reserved.

\section{Introduction}

Members of the genus Vesivirus in the family Caliciviridae infect both marine and terrestrial organisms (Smith

\footnotetext{
* Corresponding author at: 2015 SW 16th Ave., Bldg 1017, Gainesville, FL 32610, USA. Tel.: +1 352392 2239x5871; fax: +1 3523929704. E-mail addresses: romeroc@vetmed.ufl.edu, romerohcarlos@gmail.com (C.H. Romero).
}

and Boyt, 1990). Among vesiviruses known collectively as the "marine vesiviruses" are 13 serotypes isolated from swine between 1932 and 1956 called vesicular exanthema of swine viruses (VESVs), which are considered foreign animal disease (FAD) agents in the USA because they sometimes cause a vesicular disease in swine clinically indistinguishable from foot-and-mouth disease. It has been proposed that the VESV strains were accidentally introduced into pig herds through the ingestion of feed contaminated with marine mammal and fish products 
harboring serologically related vesiviruses (Smith et al., 1973). Working with these viruses requires their handling in at least a BSL-2 plus or enhanced biosafety laboratory and special USDA-APHIS permits. Due to these restrictions, research on marine vesiviruses has been hampered and diagnostic reagents are not readily available to study the distribution and impact of marine vesiviruses in marine or terrestrial animals. The identification of marine vesiviruses initially relied on virus isolation in cell culture and virus neutralization (VN) using panels of specific antisera raised against different isolates (Smith and Akers, 1976; Smith and Boyt, 1990). Although more than 45 serotypes have been established with this approach, the extent of serotypic diversity among these viruses in not known. In recent years, molecular approaches have been developed to detect and genotype new isolates (McClenahan et al., 2008; Reid et al., 1999, 2007).

Although the genotype of new isolates can be determined by nucleotide sequencing and phylogenetic analyses (Berke et al., 1997; Ganova-Raeva et al., 2004; McClenahan et al., 2008; Neill, 1992), additional studies are needed to understand the relationship between genotype and serotype. Moreover, the availability of non-restricted (non-infectious) vesivirus serologic assays would facilitate studies of the natural history of marine vesiviruses in their vast ecosystem. In this context, viruslike particles (VLPs) are empty viral capsids that resemble the capsid of the native virus, but that do not contain the infectious viral RNA that characterizes all members of the family Caliciviridae (Ball et al., 1996; Bertolotti-Ciarlet et al., 2003; Di Martino et al., 2007; Jiang et al., 1992; Laurent et al., 1994; Noad and Roy, 2003). The generation of the first calicivirus VLPs was reported for the Norwalk virus, a member of the genus Norovirus, following coexpression of ORF2 and ORF3 in a single baculovirus (Jiang et al., 1992). In members of the genus Vesivirus, the complete capsid gene (ORF2) is translated as a precursor protein approximately $73 \mathrm{kDa}$ that is cleaved by the viral protease encoded in ORF1 to generate a mature capsid protein (VP1) of approximately $60 \mathrm{kDa}$ (Carter et al., 1992; Neill et al., 1991). Virus-like particles have also been produced from the vesivirus feline calicivirus (FCV) by expressing either the capsid precursor or mature capsid protein in a baculovirus expression system (DeSilver et al., 1997; Di Martino et al., 2007). However, although the development of marine vesivirus VLPs has not been reported, recombinant antigens of broader reactivity to detect marine vesivirus antibodies have been recently described; i.e., a recombinant antigen (D3A) of 293 amino acids corresponding to a capsid fragment of San Miguel sea lion virus 5 (SMSV-5) expressed in a bacterial system was reactive with antisera to more than 30 different serotypes of marine vesiviruses (Kurth et al., 2006a). The antigen was also used to detect vesivirus antibodies in 15\% $(n=693)$ of serum samples from sick and healthy cattle (Kurth et al., 2006a), and in the serum of mares that had aborted; in which an increase in the frequency of antibodies from 47.1 to $88.2 \%$ was demonstrated (Kurth et al., 2006b).

We recently reported the isolation and characterization of two unique marine vesivirus genotypes from Steller sea lions (SSL-Eumetopias jubatus), SSL V810 and SSL V1415
(McClenahan et al., 2008). We report here the production of VLPs from these two genotypes by expression of their mature VP1 or VP1 and VP2 capsid proteins in a baculovirus system. The VLPs were utilized as antigens to develop an enzyme linked immunosorbent assay (ELISA) for the detection of serum antibodies to marine vesiviruses in animals from two free-ranging populations of SSL in Alaska.

\section{Materials and methods}

\subsection{Viral RNA}

Marine vesiviruses SSL V810 and SSL V1415 were isolated from Alaskan Steller sea lions in Vero and Madin Darby canine kidney (MDCK) cell cultures, respectively (McClenahan et al., 2008). After the fourth passage in Vero cell cultures, total RNA was extracted from the cell monolayers at the height of cytopathogenic activity using TRIzol-LS (Invitrogen, Carlsbad, CA) following the manufacturer's protocol.

\subsection{Construction of recombinant baculoviruses}

Oligonucleotide primers were designed to amplify the mature capsid gene (VP1) from the SSL vesiviruses V810 and V1415. Primers BacVFW-ORF2 (CACCATGTCGGATGGTCCAG) and BacVRV-ORF2 (TCCAAAATTTGCATAATTCAT) were used to amplify a fragment of approximately 1680 nucleotides (nt). During natural vesivirus infection, the mature capsid protein is produced post-translationally after cleavage of the full-length precursor of the capsid protein by the virus-encoded proteinase, so an ATG sequence was engineered into the forward primer. Separate baculovirus constructs were also created to express the VP1 and the protein product of ORF 3 (VP2) from a single template. BacVFW-ORF2 was used as the forward primer and BacVRV-ORF3 (GCAACCTACCAATTAACTAATTC) as the reverse primer to generate a PCR fragment of approximately $2170 \mathrm{nt}$.

All amplified PCR products were cloned into the Gateway vector, pENTR (Invitrogen) by Topo cloning and plasmids containing the desired inserts were verified by sequence analysis. Plasmid DNA was then added to a reaction mix containing baculovirus DNA (Baculodirect kit, Invitrogen), and the recombination reaction was performed according to the manufacturer's instructions. A transfection mixture was prepared that contained $250 \mathrm{ng}$ recombinant baculovirus DNA, $6 \mu \mathrm{l}$ of Cellfectin (Invitrogen), and $2 \mathrm{ml}$ unsupplemented Grace's Medium (Invitrogen). Following incubation at room temperature for $45 \mathrm{~min}$, the mixture was added to Sf-9 cells seeded at $8 \times 10^{5}$ cells per well in a 6 -well plate. The transfection mixture and cells were incubated for $5 \mathrm{~h}$ at $28^{\circ} \mathrm{C}$, after which the transfection mixture was removed and replaced with $2 \mathrm{ml}$ serum-free HyQ Medium (HyClone, Logan, UT) containing $100 \mathrm{mg} / \mathrm{ml}$ ganciclovir, as a negative selection agent, and supplemented with penicillin, streptomycin and Amphotericin B. The cultures were incubated at $28^{\circ} \mathrm{C}$ for 5 days and the cells and supernatants were harvested as the first passage (P1) viral stock. The P1 viral stock (5 $\mu \mathrm{l})$ 
was added to a fresh Sf-9 monolayer in the well of a 6-well plate and maintained in the presence of $100 \mathrm{mg} / \mathrm{ml}$ ganciclovir for $120 \mathrm{~h}$. The resulting P2 viral stock was verified as free of wild-type baculovirus with a $\beta$-gal kit (Invitrogen), and then used to infect a $100 \mathrm{ml}$ suspension culture of Sf- 9 cells at a multiplicity of infection (MOI) of 0.5 in the absence of ganciclovir. The resulting P3 viral stock was titrated by plaque assay on Sf- 9 cell cultures in 6 -well plates, and used to infect Sf-9 suspension cultures at a MOI of 3 for protein expression and purification.

\subsection{Protein purification}

Recombinant viruses were propagated in suspension cultures of Sf- 9 cells grown in 150-ml of HyQ medium. Five days post-infection the cultures were harvested, frozen and thawed twice, and clarified by low-speed centrifugation. The supernatants were layered onto a $25 \%$ sucrose cushion and subjected to centrifugation in a SW28 rotor at $24,000 \mathrm{rpm}$ for $4 \mathrm{~h}$ at $4{ }^{\circ} \mathrm{C}$. The resulting pellets were dissolved in phosphate buffered saline (PBS) pH 7.5 and further purified through a cesium chloride $(\mathrm{CsCl})$ gradient. The samples were mixed with $1.6 \mathrm{~g} / \mathrm{cm}^{3}$ of $\mathrm{CsCl}$ to produce a final density of $1.38 \mathrm{~g} / \mathrm{cm}^{3}$ as verified by refractometry. The samples were centrifuged in a SW55Ti rotor at $48,000 \mathrm{rpm}$ for $18 \mathrm{~h}$ at $15^{\circ} \mathrm{C}$ and visible bands were collected with a needle and syringe. The collected fractions were dialyzed against PBS to remove the $\mathrm{CsCl}$ using a SlideA-Lyzer cassette (Pierce, Rockford, IL), and the protein concentration was determined with a commercial Bradford assay kit (Pierce).

\subsection{SDS-PAGE and immunoblotting}

The protein samples were mixed with sample loading buffer containing $2 \%$ sodium-dodecyl sulfate (SDS), $0.5 \mathrm{M}$ Tris- $\mathrm{HCl}, \mathrm{pH} 6.8,25 \%$ glycerol, $0.5 \%$ bromophenol blue, and $2 \%$ beta-mercaptoethanol and heated at $95{ }^{\circ} \mathrm{C}$ for $5 \mathrm{~min}$. The denatured proteins were resolved by SDS polyacrylamide gel electrophoresis (SDS-PAGE) in 4-20\% gradient gels (Lonza, Basel, Switzerland) run at $125 \mathrm{~V}$ for $1.5 \mathrm{~h}$ with a protein standard (Invitrogen). Proteins were transferred onto a polyvinylidene difluoride (PVDF) membrane (Invitrogen) for $7 \mathrm{~min}$ using the iBlot Gel Transfer Device (Invitrogen). In the immunoblot analysis, the PVDF membrane was blocked for $1 \mathrm{~h}$ at room temperature in Blotto buffer ( $5 \%$ dried non-fat milk in PBS). The membrane was then incubated with a mixture of polyclonal antisera specific for SMSV serotypes; 1, 2, 4, 5, 6, 9, 10, 11, and 13, diluted to 1:2000 in Blotto, incubated for $1 \mathrm{~h}$ with shaking and then overnight at $4{ }^{\circ} \mathrm{C}$. The membrane was washed four times, 5 min each time, with Western Breeze wash buffer (Invitrogen) and incubated at room temperature for $1 \mathrm{~h}$ with goat anti-rabbit IgG-alkaline phosphatase conjugate (Pierce) (diluted 1:1000 in blocking buffer) in order to detect binding of the primary antibodies. The membrane was washed four times for 10 min before incubation with the substrate BCIP/NBT (Zymed lab, South San Francisco, CA) for $5 \mathrm{~min}$ at room temperature. The reaction was stopped with water and the membranes were dried prior to photography.

\subsection{Electron microscopy}

Electron microscopy was used to visualize the VLPs expressed from the recombinant baculoviruses. The purified VLPs were adsorbed onto Formvar-coated grids, stained with phosphotungstic acid (PTA), blotted dry, and examined with a FEI Tecnai 12 electron microscope.

\subsection{Enzyme linked immunosorbent assay}

The VLPs produced from recombinant baculoviruses expressing the mature capsid protein VP1 of vesivirus isolates SSL V810 and SSL V1415 were each employed as an antigen in the development of an ELISA modeled on previously described assays (Barajas-Rojas et al., 1993; Crowther, 2001; Ferris and Oxtoby, 1994; Kurth et al., 2006a,b). The VLPs were diluted in carbonate-bicarbonate buffer $\mathrm{pH} 9.5$ (Sigma) to a final concentration of $1 \mu \mathrm{g} / \mathrm{ml}$ and $100 \mu$ l of the dilution was added per well of a 96-well MaxiSorp polystyrene plate (Nunc, Roskilde, Denmark). Following adsorption of the antigen at $4{ }^{\circ} \mathrm{C}$ overnight, the wells were washed once with $200 \mu$ l wash buffer (Trisbuffered saline with $0.1 \%$ Tween 20 [TBST]) and blocked with $200 \mu \mathrm{l}$ of blocking buffer ( $5 \%$ non-fat dried milk in TBST) for $1 \mathrm{~h}$ at $37^{\circ} \mathrm{C}$. Rabbit polyclonal antisera against various SMSV and VESV serotypes and serum or plasma collected from free-ranging marine mammals (primary reagents) were titrated by performing serial two-fold dilutions in the plate beginning at a 1:50 dilution in TBST containing 1\% non-fat dried milk (TBST-blotto). Each serum sample was also tested in at least three wells not coated with VLPs (no antigen wells) to determine its non-specific absorbance background. The plates were incubated for $1 \mathrm{~h}$ at $37^{\circ} \mathrm{C}$ and subsequently washed six times with TBST buffer. The optimal dilution (1:3000) of the secondary reagent, protein A-peroxidase conjugate, was determined by checkerboard titration of a $0.5 \mu \mathrm{g} / \mathrm{ml}$ stock(Pierce) diluted in TBST-blotto, and $100 \mu \mathrm{l}$ of the optimal dilution was added to each well. The plate was incubated at $37^{\circ} \mathrm{C}$ for $1 \mathrm{~h}$, followed by four washes with $200 \mu \mathrm{l}$ of TBST per well. The ABTS (2,2'-azino-bis 3ethylbenzthiazoline-6-sulfonic acid; Kirkegaard \& Perry Laboratories, Gaithersburg, MD) substrate $(100 \mu \mathrm{l})$ was added to each well and the plates were incubated for $30 \mathrm{~min}$ at room temperature. The absorbance of each reaction was read at $405 \mathrm{~nm}$ on a Synergy plate reader (Bio-Tek, Winooski, VT). A serum sample was considered to contain antibodies to marine vesiviruses if two criteria were met simultaneously. First, the corrected absorbance value (VLP antigen absorbance minus no antigen absorbance) was 0.200 or greater, and second, if the index was equal or greater than 2.0 (VLP antigen absorbance divided by no antigen absorbance). Each serum sample was tested in triplicate in the blank wells. The titer for each serum sample was expressed as the reciprocal of the highest dilution that was positive by the two criteria above.

\subsection{Serum and plasma samples assayed in the ELISA and virus neutralization test}

Hyperimmune reference sera prepared in rabbits specific for the various SMSV and VESV strains (Seal 
et al., 1995) were obtained from the National Animal Disease Center, USDA, Ames, Iowa, and were assayed for their reactivity in the ELISA. These included sera specific for SMSV 1, 2, 4, 5, 6, 7, 9, 10, 11, 13, VESV-A48, B51, C52, D53, E54, F55, G55, H54, I55, J56, K54, and 1934B. Hyperimmune sera raised against FCV and mink calicivirus (MCV), both members of the genus Vesivirus were also examined. Serum samples were obtained from free-ranging SSL, including 41 samples from Southeastern Alaska collected in 2004 and 17 SSL samples from the Aleutian Islands, Alaska, collected in 2005. Some sera were stored at $4{ }^{\circ} \mathrm{C}$ for several days before long-term storage at $-20^{\circ} \mathrm{C}$ or $-70^{\circ} \mathrm{C}$. The virus neutralization (VN) test was performed as previously described (McClenahan et al., 2008).

\section{Results}

\subsection{Baculovirus expression of vesivirus capsid proteins}

Recombinant baculoviruses expressing the VP1 protein from SSL vesiviruses V810 and V1415 were constructed by inserting an $\sim 1680$-bp fragment of the vesiviruses VP1 gene into the baculovirus genome. A third recombinant baculovirus was constructed by insertion of an $\sim 2170$-bp fragment corresponding to the V810 VP1 + VP2 genes into the baculovirus genome. These recombinant viruses were propagated twice in Sf-9 cell cultures, in the presence of ganciclovir to screen out non-recombinant wild-type baculovirus. Recombinant baculoviruses expressing V810 VP1, V1415 VP1, or V810 VP1 + VP2 were titrated in a plaque-forming assay and exhibited titers of $2.3 \times 10^{7}$, $2.5 \times 10^{7}$, and $3.0 \times 10^{7} \mathrm{PFU} / \mathrm{ml}$, respectively. Each of the three recombinant baculoviruses was used to infect 150 $\mathrm{ml}$ suspensions of Sf-9 cell cultures at a MOI of 3. A $500 \mu \mathrm{l}$ sample was collected daily and the cell viability was determined. Cell viability was over $95 \%$ prior to infection and decreased over time, reaching 30\% viability at day 5 in all three infected cell cultures. Daily samples collected on days 1 through 5 were analyzed by SDS-PAGE for protein expression. The presence of an approximately $60 \mathrm{kDa}$ protein was apparent in extracts from the infected cell pellets and in supernatants harvested from all three recombinant baculoviruses, but not in the mock infected cell controls (Fig. 1A-C). The baculovirus-infected material was then subjected to isopycnic centrifugation as described in Section 2. A visible band corresponding to a density of $1.29 \mathrm{~g} / \mathrm{cm}^{3}$ was evident in the upper half of the $\mathrm{CsCl}$ gradient, consistent with the isolation of recombinant VLPS. The analysis of the material in this band by SDS-PAGE showed the presence of an expected $60 \mathrm{kDa}$ protein
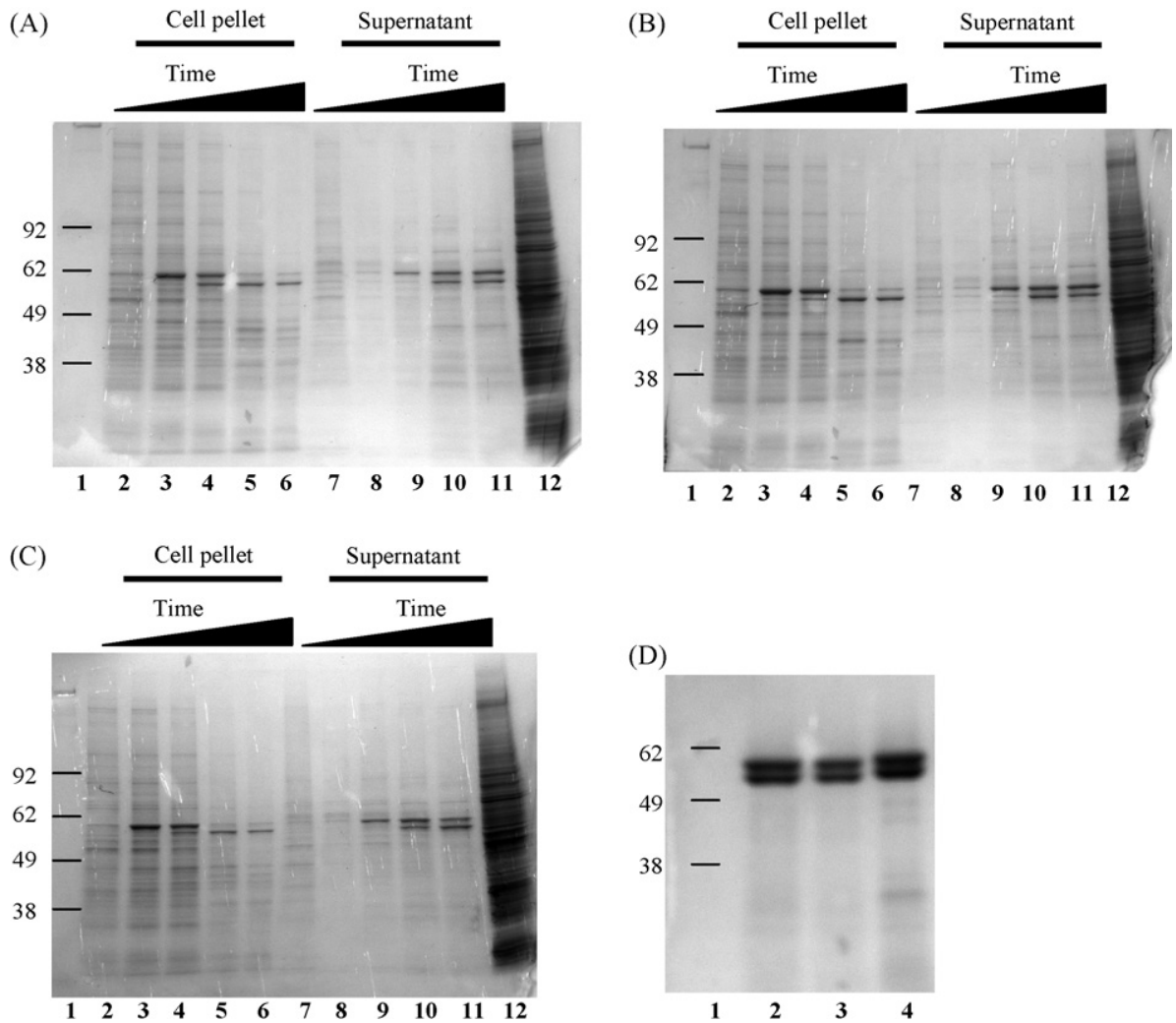

Fig. 1. SDS-PAGE analysis of SSL vesivirus proteins produced in the baculovirus expression system. Proteins were separated by SDS-PAGE and stained with Gel Code Blue (Invitrogen). (Panels A-C) Samples were harvested daily for 5 days from recombinant baculovirus-infected Sf- 9 cell cultures. Lane 1: molecular weight marker, lanes 2 through 6: daily collections from cell pellets, lanes 7 through 11: daily collections from cell culture supernatant, lane 12 : uninfected Sf-9 cell control. (Panel A) V810 VP1, (panel B) V1415 VP1, (panel C) V810 VP1 + VP2, (panel D) proteins purified from cesium chloride gradients of the supernatant from day 5 from the 3 recombinant viruses. Lane 1: molecular weight marker, lane 2: V810 VP1, lane 3: V1415 VP1, lane 4: V810 VP1 + VP2. 

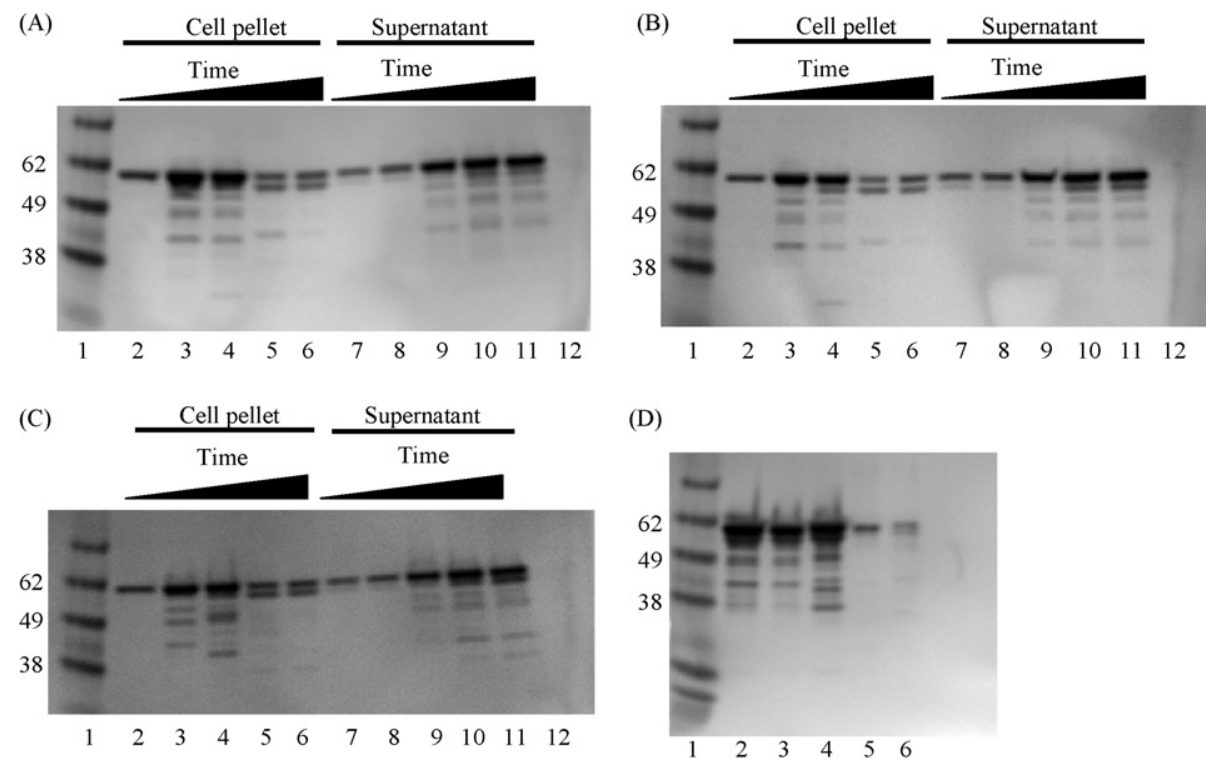

Fig. 2. Immunoblot analysis of SSL vesivirus VP1 proteins expressed in the baculovirus expression system. The panels are the same as described above for Fig. 1. The viral proteins were detected using a 1:2000 dilution of a mixture of type specific antibodies to San Miguel sea lion virus (SMSV) serotypes 4, 6,9 , 10, 11, and 13. A $60 \mathrm{kDa}$ protein consistent with the positive control vesiviruses V810 and V1415 (panel D, lanes 5 and 6 ) was detected from the daily samples and from VLPs purified in cesium chloride gradients.

(Fig. 1D). A protein of approximately $58 \mathrm{kDa}$ co-purified with the capsid protein in the $\mathrm{CsCl}$ gradient, but its identity was not determined (Fig. 1D), consistent with the appearance of "doublet" bands observed sometimes in capsid expression studies of the caliciviruses (Belliot et al., 2001; Kitamoto et al., 2002; Taube et al., 2005). Additional studies will be needed to determine whether the smaller $58 \mathrm{kDa}$ vesivirus protein was generated by mechanisms such as proteolytic cleavage (degradation), alternative processing in the baculovirus system, or initiation from an internal methionine on the messenger RNA.

A time course analysis of VP1 expression in insect cells was examined by immunoblotting. Baculovirus-infected Sf-9 cell lysates in the blot were probed with a mixture of hyperimmune sera raised against SMSV strains as described in Section 2.4. A protein of approximately $60 \mathrm{kDa}$ was detected that increased in intensity over time
(Fig. 2A-C). This protein corresponded in size to the mature VP1 protein detected in lysates of Vero cell cultures infected with SSL vesiviruses V810 and V1415 (Fig. 2D).

\subsection{Electron microscopy}

Negative staining and electron microscopy of purified protein samples from both VP1 recombinants and the VP1 + VP2 recombinant baculoviruses revealed the presence of VLPs consistent in size (32-35 nm) and shape to native calicivirus virions (Fig. 3).

\subsection{Detection of vesivirus antibodies by ELISA}

\subsubsection{ELISA antibody titers of SMSV and VESV antisera}

The reactivities of a panel of rabbit hyperimmune sera directed against several SMSV and VESV strains of varying
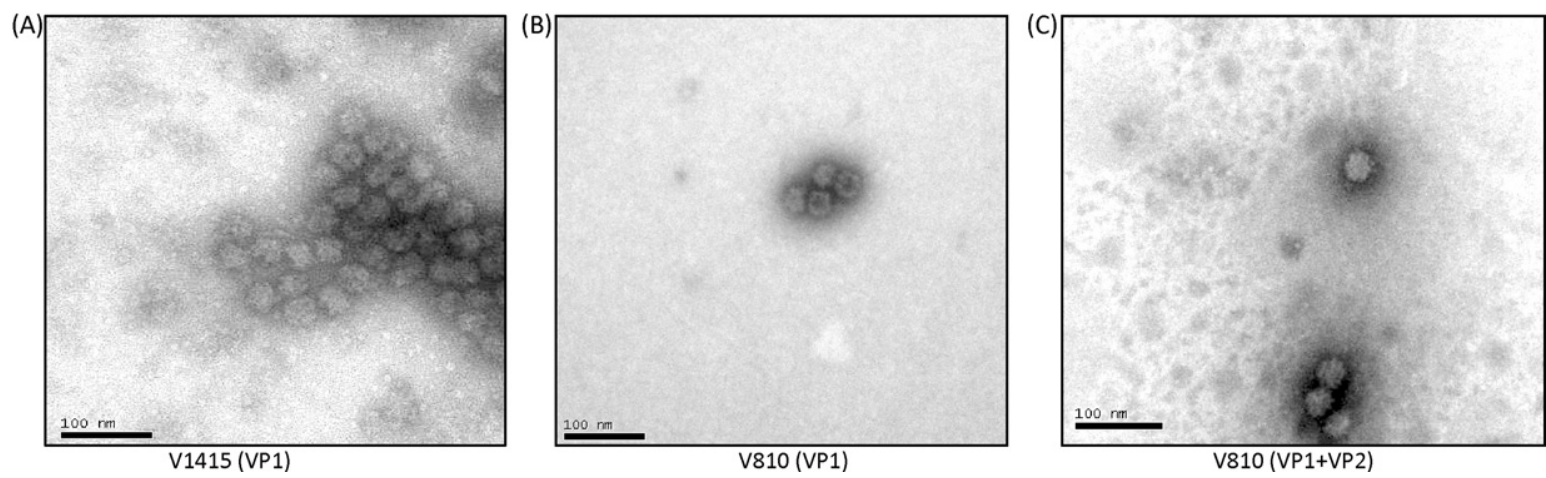

Fig. 3. Electron micrograph of virus-like particles (VLPs) expressed in the baculovirus expression system. Proteins were visualized by negative staining with phosphotungstic acid. Shown are representative images of VLPs derived from vesivirus strain: V1415 (VP1 only-panel A), V810 (VP1 only-panel B), and V810 (VP1 + VP2-panel C). 
Table 1

Antibody titers obtained by virus neutralization (VN) and enzyme linked immunosorbent assay (ELISA). Specific antisera to various marine vesiviruses (SMSV) and vesicular exanthema of swine virus (VESV), as well as antisera to feline calicivirus and mink calicivirus VLPs were assayed by VN with infectious virus and by ELISA with VLP antigens. ND: not done.

\begin{tabular}{|c|c|c|c|c|}
\hline Antiserum & V810 VLP ELISA titer & V810 VN titer & V1415 VLP ELISA titer & V1415 VN titer \\
\hline SMSV-1 & 6,400 & $<4$ & 3,200 & $<4$ \\
\hline SMSV-2 & 12,800 & $<4$ & 6,400 & $<4$ \\
\hline SMSV-4 & 3,200 & $<4$ & 3,200 & $<4$ \\
\hline SMSV-5 & $\geq 25,600$ & $<4$ & $\geq 25,600$ & $<4$ \\
\hline SMSV-6 & 200 & $<4$ & 200 & $<4$ \\
\hline SMSV-7 & $\geq 25,600$ & $<4$ & $\geq 25,600$ & $<4$ \\
\hline SMSV-9 & 6,400 & $<4$ & 6,400 & $<4$ \\
\hline SMSV-10 & 12,800 & $<4$ & 6,400 & $<4$ \\
\hline SMSV-11 & 6,400 & $<4$ & 6,400 & $<4$ \\
\hline SMSV-13 & $\geq 25,600$ & $<4$ & $\geq 25,600$ & $<4$ \\
\hline VESV-A48 & 800 & $<4$ & 1,600 & $<4$ \\
\hline VESV-B51 & 3,200 & $<4$ & 3,200 & $<4$ \\
\hline VESV-C52 & 6,400 & $<4$ & $\geq 25,600$ & $<4$ \\
\hline VESV-D53 & $\geq 25,600$ & 4 & $\geq 25,600$ & 4 \\
\hline VESV-E54 & 6,400 & $<4$ & 12,800 & $<4$ \\
\hline VESV-F55 & 1,600 & $<4$ & 3,200 & $<4$ \\
\hline VESV-G55 & 12,800 & $<4$ & 12,800 & $<4$ \\
\hline VESV-H54 & 12,800 & $<4$ & 12,800 & $<4$ \\
\hline VESV-I55 & 12,800 & $<4$ & 12,800 & $<4$ \\
\hline VESV-J56 & 3,200 & $<4$ & 3,200 & $<4$ \\
\hline VESV-K54 & 3,200 & $<4$ & 3,200 & $<4$ \\
\hline VESV-1934B & $\geq 25,600$ & $<4$ & $\geq 25,600$ & $<4$ \\
\hline Feline calicivirus & $\geq 25,600$ & ND & $\geq 25,600$ & ND \\
\hline Mink calicivirus & 800 & ND & 1,600 & ND \\
\hline
\end{tabular}

serotype were examined in the ELISA using SSL vesiviruses V810 and V1415 VLPs (Table 1). SMSV antiserum titers ranged from 200 to $\geq 25,600$, while VESV antiserum titers ranged between 800 and $\geq 25,600$ when tested against V810 VLPs. SMSV antiserum titers ranged from 200 to $\geq 25,600$ while VESV antiserum titers ranged between 1,600 and $\geq 25,600$ when assayed against V1415 VLPs. Specific antisera raised against other Vesivirus genus members including FCV and MCV virions also reacted with SSL vesivirus VLPs with titers as high as $\geq 25,600$ for FCV antiserum, and 800 and 1600 for MCV antiserum (Table 1).

\subsubsection{ELISA titers of marine mammal sera}

A total of 58 serum samples obtained in 2004 from freeranging marine mammals from Southeast Alaska, and in 2005 from the Aleutian Islands, Alaska, were tested in the V810 and V1415 ELISA for specific antibodies. When 41 sera collected from young free-ranging SSL from Southeast Alaska were assayed by ELISA, 36 (87.8\%) were positive for antibodies reacting with the V810 VLPs and 38 (92.7\%) were positive for the V1415 VLPs (Table 2). Antibody titers against isolate V810 VLPs ranged from 50 to 800 with a median of 200 while titers against isolate V1415 VLPs ranged from 100 to 12,800 with a median of 400 (not shown). Virus neutralizing antibody titers were demonstrated in 27 (65.9\%) of 41 sera tested against isolate V810 and in 38 (92.7\%) of 41 sera tested against isolate V1415 (Table 2). The median VN antibody titer was 16 against isolate V810 and 512 against isolate V1415 (not shown). Except for four borderline results, all 17 sera obtained in 2005 from SSL from the Aleutian Islands were negative for ELISA vesivirus antibodies. The same $17 \mathrm{SSL}$ sera were also negative for VN antibodies against isolates V810 and V1415 (Table 2).

\section{Discussion}

The major capsid protein (VP1) of two recently characterized SSL vesiviruses; V810 and V1415, was expressed in the baculovirus system. The expressed VP1 (with or without the presence of VP2) self-assembled into VLPs. This is an advance in the study of marine vesiviruses because recombinant VLPs are nearly indistinguishable from native virions, and therefore have the potential for use as non-infectious antigens in diagnostics assays (Ball et al., 1996). In the host, after natural infection with caliciviruses, the most abundantly produced antibodies are directed against the capsid protein, and a significant proportion of these antibodies have type-specific neutralizing activity (Guiver et al., 1992; Matsuura et al., 2001; Neill et al., 1991; Tohya et al., 1991). The availability of recombinant VLPs should also facilitate the study of antigenic relationships among the marine vesiviruses by providing an unlimited supply of immunogens for the production of antisera against structural (capsid) proteins. Such sera would enable the rapid characterization of new vesivirus strains, and provide reference standards in the development and validation of diagnostic assays.

Although vesiviruses encode a precursor of the capsid protein in ORF2, we engineered the baculoviruses to express only the predicted processed form of the VP1 by engineering an ATG codon at the 5'-end of the VP1 gene cloned into the recombinant baculovirus. In addition, a recombinant baculovirus also yielded VLPs when the complete VP2 gene sequences encoded in ORF3 were included with those of the VP1. Like other caliciviruses, the VP1 gene of marine vesiviruses alone seems sufficient for assembly of the VLPs and the co-expression of VP2 is not necessary for capsid formation (Bertolotti-Ciarlet et al., 
Table 2

Antibody titers in the serum of Steller sea lions against marine vesiviruses as determined by virus neutralization (VN) using isolates V810 and V1415 and ELISA using VLPs from the same isolates as antigen. SSL: Steller sea lion; SE: Southeast Alaska; AL: Aleutian Islands, Alaska.

\begin{tabular}{|c|c|c|c|c|}
\hline Serum sample & V810 VLP ELISA titer & V810 VN titer & V1415 VLP ELISA titer & V1415 VN titer \\
\hline SSL2004-499SE & 200 & $<4$ & 800 & 128 \\
\hline SSL2004-500SE & 100 & $<4$ & 800 & $\geq 8192$ \\
\hline SSL2004-501SE & 100 & 4 & 800 & 512 \\
\hline SSL2004-502SE & $<50$ & $<4$ & $<50$ & 16 \\
\hline SSL2004-503SE & 200 & 4 & 800 & 512 \\
\hline SSL2004-504SE & 400 & $<4$ & 400 & 8 \\
\hline SSL2004-505SE & 400 & $<4$ & 800 & 64 \\
\hline SSL2004-506SE & 200 & 1024 & 200 & 512 \\
\hline SSL2004-507SE & 400 & 4 & 400 & 1024 \\
\hline SSL2004-508SE & 50 & 32 & 800 & 512 \\
\hline SSL2004-509SE & 800 & 16 & 200 & 2048 \\
\hline SSL2004-510SE & 200 & 8 & 400 & 256 \\
\hline SSL2004-511SE & 200 & 16 & 800 & 4096 \\
\hline SSL2004-512SE & $<50$ & 8 & 200 & $\geq 8192$ \\
\hline SSL2004-513SE & 200 & 4 & 3,200 & 16 \\
\hline SSL2004-514SE & 400 & 32 & 6,400 & 512 \\
\hline SSL2004-515SE & 50 & $<4$ & 400 & 512 \\
\hline SSL2004-516SE & 100 & $<4$ & 100 & 32 \\
\hline SSL2004-517SE & 400 & $<4$ & 12,800 & 1024 \\
\hline SSL2004-518SE & 100 & $<4$ & 800 & 4096 \\
\hline SSL2004-519SE & 100 & 128 & 200 & 2048 \\
\hline SSL2004-520SE & 200 & 64 & 1,600 & 2048 \\
\hline SSL2004-521SE & 100 & $<4$ & 100 & 32 \\
\hline SSL2004-522SE & 400 & 16 & 800 & 8 \\
\hline SSL2004-523SE & 200 & 4 & 200 & 8 \\
\hline SSL2004-524SE & 800 & 64 & 3,200 & 2048 \\
\hline SSL2004-525SE & 800 & 16 & 800 & $<4$ \\
\hline SSL2004-526SE & 100 & 32 & 200 & 8 \\
\hline SSL2004-527SE & 800 & 16 & 400 & $<4$ \\
\hline SSL2004-528SE & 400 & 4 & 800 & 1024 \\
\hline SSL2004-529SE & 50 & 4 & 200 & $<4$ \\
\hline SSL2004-530SE & 100 & 4 & 200 & 128 \\
\hline SSL2004-531SE & 100 & 16 & 800 & 2048 \\
\hline SSL2004-532SE & 50 & 64 & 200 & 64 \\
\hline SSL2004-533SE & 200 & 8 & 3,200 & $\geq 8192$ \\
\hline SSL2004-534SE & 800 & 1024 & 400 & 8 \\
\hline SSL2004-535SE & $<50$ & 8 & $<50$ & 128 \\
\hline SSL2004-536SE & 100 & $<4$ & 400 & 1024 \\
\hline SSL2004-537SE & $<50$ & $<4$ & 200 & 1024 \\
\hline SSL2004-538SE & 100 & $<4$ & 200 & 512 \\
\hline SSL2004-539SE & $<50$ & $<4$ & $<50$ & 8 \\
\hline SSL2005-594AL & $<50$ & $<4$ & $<50$ & $<4$ \\
\hline SSL2005-595AL & $<50$ & $<4$ & $<50$ & $<4$ \\
\hline SSL2005-596AL & $<50$ & $<4$ & 50 & $<4$ \\
\hline SSL2005-597AL & $<50$ & $<4$ & $<50$ & $<4$ \\
\hline SSL2005-598AL & $<50$ & $<4$ & $<50$ & $<4$ \\
\hline SSL2005-599AL & 50 & $<4$ & $<50$ & $<4$ \\
\hline SSL2005-600AL & $<50$ & $<4$ & $<50$ & $<4$ \\
\hline SSL2005-601AL & $<50$ & $<4$ & $<50$ & $<4$ \\
\hline SSL2005-602AL & 50 & $<4$ & 50 & $<4$ \\
\hline SSL2005-603AL & $<50$ & $<4$ & $<50$ & $<4$ \\
\hline SSL2005-604AL & 50 & $<4$ & 50 & $<4$ \\
\hline SSL2005-605AL & $<50$ & $<4$ & $<50$ & $<4$ \\
\hline SSL2005-606AL & $<50$ & $<4$ & $<50$ & $<4$ \\
\hline SSL2005-607AL & $<50$ & $<4$ & $<50$ & $<4$ \\
\hline SSL2005-608AL & $<50$ & $<4$ & $<50$ & $<4$ \\
\hline SSL2005-609AL & $<50$ & $<4$ & $<50$ & $<4$ \\
\hline SSL2005-610AL & $<50$ & $<4$ & $<50$ & $<4$ \\
\hline
\end{tabular}

2003; Di Martino et al., 2007). The ORF3 protein product has an unknown function, but due to the basic characteristic of the VP2 protein, it has been proposed to interact with the viral RNA and possibly, to encapsidate the RNA of progeny viruses (Neill et al., 1991; Prasad et al., 1999). The VP2 protein has been shown to be a structural protein (Glass et al., 2000; Sosnovtsev and Green, 2000), and is necessary for infection of FCV (Sosnovtsev et al., 2005). Previous experiments with noroviruses indicated that VLPs expressed from ORF2 and ORF3 sequences had higher yields than when expressed from ORF2 alone, and the VLPs showed increased stability (Bertolotti-Ciarlet et al., 2003). In the present study, it appeared that the V810 vesivirus VLPs produced with both VP1 + VP2 genes exemplified the 
traditional "cup-like" morphology of members of the Caliciviridae, but further experimentation will be needed to determine whether there are advantages to co-expressing VP1 and VP2 of these marine vesiviruses.

A new ELISA was developed using non-infectious VLPS expressed from recombinant baculoviruses as antigen coated on microtiter plate wells. Rabbit origin typing sera against 22 marine vesiviruses (10 serotypes designated SMSVs and 12 serotypes designated VESVs) were crossreactive with VLPs produced from SSL vesivirus strains V810 and V1415. However, none of these antisera neutralized SSL isolates V810 and V1415, indicating that these two viruses did not belong to any of the known VESV or SMSV serotypes tested. These findings also indicated that the V810 and V1415 VLPs can serve as broadly reactive antigens, which recognize antibodies against many known marine vesivirus types and strains. Recently described ELISAs for the detection of antibodies against marine vesiviruses have in addition to the VLPs reported here, used both a bacterially expressed peptide, D3A and pooled whole viruses (SMSVs 5, 13, and 17) as coating antigens (Kurth et al., 2006a,b; Smith et al., 2006). These ELISA coating antigens were reported to be cross-reactive with more than 14 different marine vesivirus serotypes, which is similar to the cross-reactivity of the VLPs described here.

The VLP-based ELISA was used in a serologic survey of Steller sea lions living near southeast Alaska in 2004 and the Aleutian Islands in 2005. Each of the 58 SSL sera was assayed by VN against vesiviruses V810 and V1415, and by ELISA against VLPs produced by recombinant baculoviruses expressing VP1 from isolates V810 and V1415. Over $90 \%$ of the tested animals in Southeast Alaska were positive for one or both vesiviruses in the ELISA. In addition, ELISA and VN antibodies against V1415 VLPs and the 2005 viral isolate V1415, respectively, were present in higher titer and frequency than similar antibodies against the V810 VLPs and the 2002 viral isolate V810. These results may reflect a more recent exposure to vesivirus SSL V1415-like strains circulating in 2004 versus vesivirus SSL V810-like strains circulating in 2002 in the same population of SSL in Southeast Alaska. An interesting finding was the identification of 17 antibody-negative serum samples collected in 2005 from SSL in the Aleutian Islands (Table 2). Further screening of SSLs from this area in the near future will be needed to determine whether animals in this rookery have remained free of exposure to marine vesiviruses.

In summary, we report the development, expression and production of VLPs of marine vesiviruses from recombinant baculoviruses, in which either the mature capsid gene VP1 or both VP1 and VP2 sequences had been introduced. These VLPs were consistent in appearance with native virions both in size and structure, and the VLPs containing VP1 were successfully used to develop an ELISA for the detection of vesivirus antibodies. The ELISA was shown to detect antibodies in reference hyperimmune rabbit sera raised in the laboratory against 24 different vesiviruses, including $12 \mathrm{VESV}$ serotypes that were isolated decades ago (1932-1956) and in the sera of free-ranging Steller sea lions undergoing natural vesivirus infection 4-7 years ago (2002-2005). The ELISA will make possible for the first time, the large-scale screening of marine mammals for infection with vesiviruses in seroepidemiological studies both in the North Pacific Ocean waters, known to be a natural habitat of these viruses (Burek et al., 2005; Skilling et al., 1987; Smith et al., 1973), as well as in the Atlantic Ocean and Gulf of Mexico waters, from where marine vesiviruses have not yet been isolated. This ELISA will contribute also to the screening of terrestrial mammals for potential exposure to pathogenic marine vesiviruses or related vesivirus strains. Because certain marine vesiviruses (VESVs) are restricted agents by virtue of inducing clinical signs in swine indistinguishable from those of foot-and-mouth disease, these safe, nonreplicating VLP antigens can now be used safely in conventional diagnostic virology laboratories and in basic calicivirus research.

\section{Acknowledgements}

This research was funded by the Marine Mammal Health Program, College of Veterinary Medicine, University of Florida, and in part by the Intramural Research Program of the NIH, NIAID. SDM was funded by the Department of Infectious Diseases and Pathology, College of Veterinary Medicine, University of Florida. Sera from marine mammals were obtained under permit numbers 358-1564-03 and 782-1889 from the National Oceanic and Atmospheric administration (NOAA), US Department of Commerce.

\section{References}

Ball, J.M., Estes, M.K., Hardy, M.E., Conner, M.E., Opekun, A.R., Graham, D.Y., 1996. Recombinant Norwalk virus-like particles as an oral vaccine. Arch. Virol. Suppl. 12, 243-249.

Barajas-Rojas, J.A., Riemann, H.P., Franti, C.E., 1993. Notes about determining the cut-off value in enzyme linked immunosorbent assay (ELISA). Prev. Vet. Med. 15, 231-233.

Belliot, G., Noel, J.S., Li, J.-F., Seto, Y., Humphrey, C.D., Ando, T., Glass, R.I., Monroe, S.S., 2001. Characterization of capsid genes, expressed in the baculovirus system, of three new genetically-distinct strains of "Norwalk-like viruses". J. Clin. Microbiol. 39, 4288-4295.

Berke, T., Golding, B., Jiang, X., Cubbitt, D.W., Wolfaart, M.A., Smith, A.W., Matson, D.O., 1997. Phylogenetic analysis of the caliciviruses. J. Med. Virol. 52, 419-424.

Bertolotti-Ciarlet, A., Crawford, S.E., Hutson, A.M., Estes, M.K., 2003. The 3' end of Norwalk virus mRNA contains determinants that regulate the expression and stability of the viral capsid protein VP1: a novel function for the VP2 protein. J. Virol. 77, 11603-11615.

Burek, K.A., Gulland, F.M.D., Sheffield, G., Beckmen, K.B., Keyes, E., Spraker, T.R., Smith, A.W., Skilling, D.E., Evermann, J.F., Stott, J.L., Saliki, J.T., Trites, A.W., 2005. Infectious disease and the decline of Steller sea lions (Eumetopias jubatus) in Alaska, USA; insights from serologic data. J. Wildl. Dis. 41, 512-524.

Carter, M.J., Milton, I.D., Meanger, J., Bennett, M., Gaskell, R.M., Turner, P.C., 1992. The complete nucleotide sequence of a feline calicivirus. Virology 190, 443-448.

Crowther, J.R., 2001. The ELISA Guidebook. Humana Press, Totowa, NJ.

DeSilver, D.A., Guimond, P.M., Gibson, J.K., Thomsen, D.R., Wardley, R.C., Lowery, D.E., 1997. Expression of the complete capsid and the hypervariable region of feline calicivirus in the baculovirus expression system. In: First International Symposium on Caliciviruses. pp. 131-143.

Di Martino, B., Marsilio, F., Roy, P., 2007. Assembly of feline calicivirus-like particles and its immunogenicity. Vet. Microbiol. 120, 173-178.

Ferris, N.P., Oxtoby, J.M., 1994. An enzyme-linked immunosorbent assay for the detection of marine caliciviruses. Vet. Microbiol. 42, 229-238.

Ganova-Raeva, L., Smith, A.W., Fields, H., Khudyakov, Y., 2004. New calicivirus isolated from walrus. Virus Res. 102, 207-213.

Glass, P.J., White, L.J., Ball, J.M., Leparc-Goffart, I., Hardy, M.E., Estes, M.K., 2000. Norwalk virus open reading frame 3 encodes a minor structural protein. J. Virol. 74, 6581-6591. 
Guiver, M., Littler, E., Caul, E.O., Fox, A.J., 1992. The cloning, sequencing and expression of a major antigenic region from the feline calicivirus capsid protein. J. Gen. Virol. 73, 2429-2433.

Jiang, X., Wang, M., Graham, D.Y., Estes, M.K., 1992. Expression, selfassembly, and antigenicity of the Norwalk virus capsid protein. J. Virol. 66, 6527-6532.

Kitamoto, N., Tanaka, T., Natori, K., Takeda, N., Nakata, S., Jiang, X., Estes, M.K. 2002. Cross-reactivity among several recombinant calicivirus-like particles (VLPs) with monoclonal antibodies obtained from mice immunized orally with one type of VLP. J. Clin. Microbiol. 40, 2459-2465.

Kurth, A., Evermann, J.F., Skilling, D.E., Matson, D.O., Smith, A.W., 2006a. Prevalence of vesivirus in a laboratory-based set of serum samples obtained from dairy and beef cattle. Am. J. Vet. Res. 67, 114-119.

Kurth, A., Skilling, D.E., Smith, A.W., 2006b. Serologic evidence of vesivirus-specific antibodies associated with abortion in horses. Am. J. Vet. Res. 67, 1033-1039.

Laurent, S., Vautherot, J.F., Madelaine, M.F., Le Gall, G., Rasschaert, D., 1994. Recombinant rabbit hemorrhagic disease virus capsid protein expressed in baculovirus self-assembles into virus-like particles and induces protection. J. Virol. 68, 6794-6798.

Matsuura, Y., Tohya, Y., Mochizuki, M., Takase, K., Sugimura, T., 2001 Identification of conformational neutralizing epitopes on the capsid protein of canine calicivirus. J. Gen. Virol. 82, 1695-1702.

McClenahan, S.D., Burek, K.A., Beckmen, K.B., Knowles, N.J., Neill, J.D. Romero, C.H., 2008. Genomic characterization of novel marine vesiviruses from Steller sea lions (Eumetopias jubatus) from Alaska. Virus Res. 138, 26-35.

Neill, J.D., 1992. Nucleotide sequence of the capsid protein gene of two serotypes of San Miguel sea lion virus: identification of conserved and non-conserved amino acid sequences among calicivirus capsid proteins. Virus Res. 24, 211-222.

Neill, J.D., Reardon, I.M., Heinrikson, R.L., 1991. Nucleotide sequence and expression of the capsid protein gene of feline calicivirus. J. Virol. 65, 5440-5447.

Noad, R., Roy, P., 2003. Virus-like particles as immunogens. Trends Microbiol. 11, 438-444.

Prasad, B.V., Hardy, M.E., Dokland, T., Bella, J., Rossmann, M.G., Estes, M.K. 1999. X-ray crystallographic structure of the Norwalk virus capsid. Science 286, 287-290.
Reid, S.M., Ansell, D.M., Ferris, N.P., Hutchings, G.H., Knowles, N.J., Smith, A.W., 1999. Development of a reverse transcription polymerase chain reaction procedure for the detection of marine caliciviruses with potential application for nucleotide sequencing. J. Virol. Methods 82, 99-107.

Reid, S.M., King, D.P., Shaw, A.E., Knowles, N.J., Hutchings, G.H., Cooper, E.J., Smith, A.W., Ferris, N.P., 2007. Development of a real-time reverse transcription polymerase chain reaction assay for detection of marine caliciviruses (genus Vesivirus). J. Virol. Methods 140, 166173.

Seal, B.S., House, J.A., Whetstone, C.A., Neill, J.D., 1995. Analysis of the serologic relationship among San Miguel sea lion virus and vesicular exanthema of swine virus isolates. Application of the western blot assay for detection of antibodies to swine sera to these virus types. J. Vet. Diagn. Invest. 7, 190-195.

Skilling, D.E., Barlough, J.E., Berry, E.S., Brown, R.F., Smith, A.W., 1987. First isolation of a calicivirus from the Steller sea lion (Eumetopias jubatus). J. Wildl. Dis. 23, 534-538.

Smith, A.W., Akers, T.G., 1976. Vesicular exanthema of swine. JAMA 169, 700-703.

Smith, A.W., Akers, T.G., Madin, S.H., Vedros, N.A., 1973. San Miguel sea lion virus isolation, preliminary characterization and relationship to vesicular exanthema of swine virus. Nature 244, 108-110.

Smith, A.W., Boyt, P.M., 1990. Caliciviruses of ocean origin: a review. J. Zoo. Wildl. Med. 21, 3-23.

Smith, A.W., Iversen, P.L., Skilling, D.E., Stein, D.A., Bok, K., Matson, D.A. 2006. Vesivirus viremia and seroprevalence in humans. J. Med. Virol. 78, 693-701.

Sosnovtsev, S.V., Belliot, G., Chang, K.O., Onwudiwe, O., Green, K.Y., 2005. Feline calicivirus VP2 is essential for the production of infectious virions. J. Virol. 79, 4012-4024.

Sosnovtsev, S.V., Green, K.Y., 2000. Identification and genomic mapping of the ORF3 and VPg proteins in feline calicivirus virions. Virology 277, 193-203.

Taube, S., Kurth, A., Schreier, E., 2005. Generation of recombinant Norovirus-like particles (VLP) in the human endothelial kidney cell line 293T. Arch. Virol. 150, 1425-1431.

Tohya, Y., Masuoka, K., Takahashi, E., Mikami, T., 1991. Neutralizing epitopes of feline calicivirus. Arch. Virol. 117, 173-181. 